\title{
Postnatal changes in concentrations of free and bound leptin
}

\author{
T K Hytinantti, M Juntunen, H A Koistinen, V A Koivisto, S-L Karonen, S Andersson
}

Helsinki City

Maternity Hospital, Helsinki, Finland

T K Hytinantti

Department of Clinical Chemistry, Helsinki University Central

Hospital

M Juntunen

S-L Karonen

Department of

Medicine, Division Of

Geriatrics, Helsinki

University Central

Hospital

$M$ Juntunen

H A Koistinen

V A Koivisto

Department of

Obstetrics and

Gynecology, Helsinki

University Central

Hospital

$S$ Andersson

Hospital for Children and Adolescents, Helsinki University

Central Hospital

$\mathrm{S}$ Andersson

Correspondence to:

Dr Hytinantti, Helsinki City

Maternity Hospital,

Sofianlehdonkatu 5, 00610

Helsinki, Finland

timo.hytinantti@hus.fi

Accepted 14 May 2001

\begin{abstract}
Aim-To evaluate the effect of maternal diabetes on the concentrations of free and bound leptin at birth and during postnatal adaptation.

Methods-Total, bound, and free leptin concentrations and the percentage of free leptin were measured in cord plasma and plasma at 3 days of age of 13 term infants of mothers with gestational diabetes mellitus (GDM) and 13 term infants of healthy mothers. Gestational age was 40.2 (1.4) weeks, and birth weight was 3693 (549) $\mathrm{g}$ (means (SD)).

Results-At birth, infants of mothers with GDM had significantly higher concentrations of total, bound, and free leptin and a higher percentage of free leptin (all $p<0.05$ ). In all infants, these concentrations were significantly lower at 3 days of age than at birth (all $p<0.003)$, and the differences in concentrations of total, bound, and free leptin between the two groups were no longer significant. In infants of mothers with GDM, the percentage of free leptin remained unchanged, and was higher $(p<0.05)$ than in infants of healthy mothers; in the latter group the percentage of free leptin significantly declined $(p=0.02)$.

Conclusions-GDM appears to influence fetoplacental leptin metabolism. This effect may be mediated through altered maternal glucose metabolism, or insulinaemia, or both.

(Arch Dis Child Fetal Neonatal Ed 2001;85:F123-F126)
\end{abstract}

Keywords: leptin; gestational diabetes mellitus; glucose metabolism

The adipocyte derived hormone leptin plays a role in a multiplicity of events in human physiology; it is involved in the regulation of energy balance and food intake, and it may also play a role in fertility and fetal development. ${ }^{1-7}$ In human circulation, leptin is found both in a free form and bound to specific binding proteins, one of them being a soluble leptin receptor. ${ }^{8}$ In vivo insulin increases total leptin concentration, ${ }^{10}{ }^{11}$ which appears to be mediated at the adipocyte level, at least in part, by insulin stimulated glucose uptake and metabolism. ${ }^{12}$ However, at present, data on the regulation of free and bound leptin are sparse. In patients with impaired glucose tolerance, a significant correlation exists between free leptin and fasting insulin levels and $\mathrm{HbAlc}{ }^{13}$ In healthy subjects and patients with insulin dependent diabetes mellitus (type 1), both maternal free and bound leptin concentrations increase during pregnancy. In addition, diabetic mothers have higher levels of soluble leptin receptor. ${ }^{14}$ Taken together, these data suggest that insulin or altered glucose metabolism, or both, may affect concentrations of free and bound leptin.

Infants of diabetic mothers have higher cord blood leptin concentrations than infants of healthy mothers. ${ }^{15-19}$ In addition, cord plasma leptin levels are influenced by the infant's birth weight, ${ }^{20-24}$ type of fetal growth, ${ }^{24-26}$ and gestational age. ${ }^{26}$ After birth, serum leptin concentrations decrease: at 6 hours of age no difference has been observed, but by 16 hours, leptin concentrations are significantly lower than at birth and remain so up to the age of 7 days. ${ }^{27-32}$

At present, there are no data on to what extent leptin circulates in free and bound forms in newborn infants. Furthermore, whether maternal gestational diabetes mellitus (GDM) affects these variables remains unknown. During the early postnatal period, total leptin concentrations decrease, ${ }^{27-32}$ but whether this decrease reflects a decrease in free or bound leptin concentrations has not been studied. This study was therefore undertaken to examine the cord plasma concentrations of free and bound leptin, and the early postnatal changes in these variables in infants of healthy mothers and those with GDM.

\section{Subjects and methods}

We studied 13 infants of normal mothers and 13 of mothers with GDM. Mean (SD) gestational age, corrected by ultrasound examination, was 40.2 (1.4) weeks and birth weight was 3693 (549) g. Relative birth weight (weight standard deviation score) was determined by reference to a Finnish newborn population of 74766 singeltons born from 1978 to $1982 .^{33}$ Weight, length, and head circumference were measured at birth, and weight was determined when the control blood sample was obtained at 3 days of age. Body mass index (BMI; weight $(\mathrm{kg}) /$ length $\left.(\mathrm{m})^{2}\right)$ was calculated, using birth length for both BMI at birth and BMI at 3 days of age. None of the infants presented with signs of hypoglycaemia or were hypoglycaemic during the study period. As part of the clinical routine, blood glucose levels are monitored for the first 24-48 hours in infants of mothers with GDM. None of these infants were hypoglycaemic as defined by blood glucose below 2.5 $\mathrm{mmol} / \mathrm{l}$. All infants were clinically normal and well. There were no differences in clinical variables between these two groups (table 1). 
Table 1 Data on infants born to either mothers with gestational diabetes mellitus (GDM) or healthy mothers

\begin{tabular}{lll}
\hline & $\begin{array}{l}\text { Infants of GDM } \\
\text { mothers }\end{array}$ & $\begin{array}{l}\text { Infants of healthy } \\
\text { mothers }\end{array}$ \\
\hline Male/female & $6 / 7$ & $6 / 7$ \\
Gestational age (weeks) & $40.2(1.4)$ & $40.3(1.4)$ \\
Range & $36.9-41.6$ & $37.1-42.4$ \\
Birth weight (g) & $3757(614)$ & $3630(491)$ \\
Range & $2570-4500$ & $2760-4740$ \\
Birth weight (SDS) & $0.3(1.0)$ & $0.0(0.9)$ \\
Range & -2.0 to 1.9 & -2.0 to 2.0 \\
Birth length (cm) & $50.3(2.3)$ & $51.0(2.4)$ \\
Range & $45.0-53.0$ & $47.0-56.0$ \\
BMI at birth & $14.7(1.4)$ & $13.9(0.7)$ \\
Range & $11.8-17.1$ & $12.5-15.1$ \\
Weight at 3 days of age (g) & $3543(565)^{\star}$ & $3415(506)^{\star}$ \\
Range & $2545-4245$ & $2580-4600$ \\
BMI at 3 days of age & $13.9(1.3)^{\star}$ & $13.1(1.0)^{\star}$ \\
Range & $11.7-16.3$ & $11.7-14.7$ \\
Weight loss by 3 days of age (g) & $214(94)$ & $215(83)$ \\
Range & $25-320$ & $100-360$ \\
Weight of the placenta (g) & $635(135)$ & $637(111)$ \\
Range & $360-850$ & $390-880$ \\
\hline
\end{tabular}

Values are mean (SD) unless otherwise indicated

${ }^{\star} \mathrm{p}<0.001$ compared with at birth.

BMI, Body mass index.

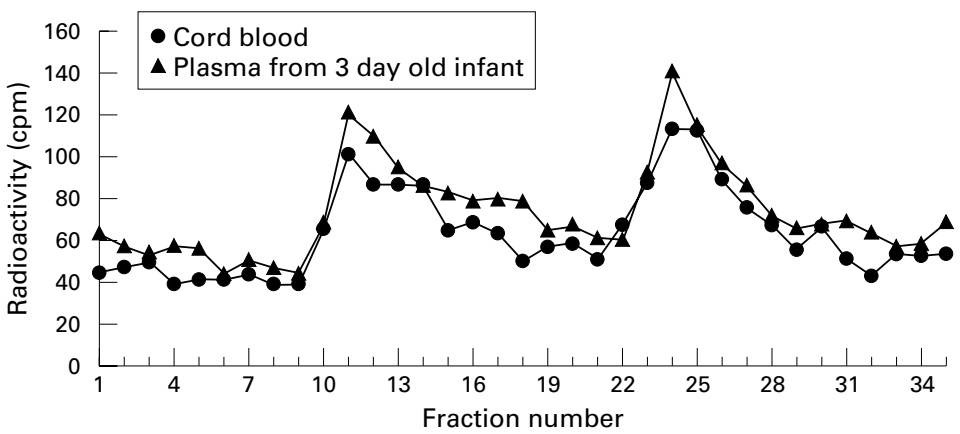

Figure 1 An example of the elution profile (high performance liquid chromatography) of the cord blood and plasma from a 3 day old infant of a mother with gestational diabetes mellitus. The first peaks show bound leptin, and the last peaks represent free leptin.

GDM was diagnosed after a $75 \mathrm{~g}$ oral glucose tolerance test according to recommendations by the Finnish committee on diagnosis and treatment of GDM..$^{34}{ }^{35}$ None of the mothers had pre-eclampsia. In our patients, GDM was treated with diet only, and none of the mothers received treatment with insulin.

The study was approved by the ethics committee of the Helsinki City Hospitals. Written informed consent of the parents was obtained before participation.

\section{METHODS}

Blood samples were drawn at birth from the umbilical vein, and, at the postpartum age of 3 days (mean (SD) 62 (12) h, range 40-87 h), a sample was taken from each infant from a superficial vein, collected into an EDTA tube, and spun for 10 minutes at $2000 \mathrm{~g}$. Plasma was stored at $-20^{\circ} \mathrm{C}$ until analysis.

\section{ASSAY OF LEPTIN}

Leptin was determined with a radioimmunoassay (Linco Research, St Charles, Missouri, USA).$^{36}$ The detection limit of this assay is 0.26 $\mu \mathrm{g} / 1$ in our laboratory as determined by calculating 2 SDs (mean of 13 assays) from a zero reference point. The intra-assay and interassay coefficients of variation at low concentration $(2.8(0.2) \mu \mathrm{g} / \mathrm{l})$ are $6.1 \%$ and $3.0 \%$, and at medium concentration $(19.6(1.4) \mu \mathrm{g} / \mathrm{l}) 6.7 \%$ and $2.2 \%$ respectively.
ASSAY OF FREE LEPTIN

Free and bound leptin concentrations were determined by high performance liquid chromatography (HPLC). In brief, $150 \mu \mathrm{l}$ plasma was incubated with $150 \mu \mathrm{l}\left[{ }^{125} \mathrm{I}\right]$ leptin (standard amount) at room temperature overnight. Samples were then diluted $1: 10$ with eluting buffer ( $0.1 \mathrm{~mol} / 1$ sodium phosphate, $\mathrm{pH} 7.2)$, and filtered through a Millex-HV $0.45 \mu \mathrm{m}$ filter (Millipore). Each cord plasma sample and three day sample was treated and eluted in parallel during the same day.

HPLC analysis was performed using LKB equipment which included a 2150 HPLC pump, 2152 controller, and 2212 Helirac (LKB, Bromma, Sweden). The column was an Ultropac column (TSK G 3000 SW; $7.5 \times 300$ $\mathrm{mm}$; LKB) equipped with a sample injector with a $100 \mu$ loop. Elution was performed with degassed $0.1 \mathrm{~mol} / 1$ sodium phosphate buffer (pH 7.2). The flow rate was constantly 1.0 $\mathrm{ml} / \mathrm{min}$, and the fraction volume was $1.0 \mathrm{ml}$. Elution time was $50 \mathrm{~min}$, and therefore we obtained 50 fractions per sample. Absorbance at $275 \mathrm{~nm}$ was monitored with a 2151 variable wavelength monitor (LKB). The radioactivity of the samples was measured with a 1282 Compugamma CS (LKB Wallac, Turku, Finland). On the elution profile, the first peaks shown are bound leptin and the last peak represents free leptin (fig 1). Peak areas were then estimated from the elution profiles.

The reproducibility of HPLC was confirmed using $\left[{ }^{125} \mathrm{I}\right]$ leptin in $1 \%$ bovine serum albumin/ phosphate buffer. Leptin was iodinated by the solid lactoperoxidase method. ${ }^{37}$ The coefficient of variation of the assay was $12 \%$. Amounts of bound and free leptin were calculated from the total leptin concentration assayed by radioimmunoassay for each sample. The percentage of free leptin was calculated as (free leptin concentration/total leptin concentration) $\times$ 100.

\section{STATISTICAL ANALYSIS}

Comparisons between groups were made by the Mann-Whitney U test. The Wilcoxon test was used for comparison of paired items. Leptin concentrations were logarithmically transformed when appropriate. Simple and multiple regression analysis were used. $\mathrm{p}<0.05$ was considered statistically significant. The patient data are given as median, $\mathrm{SD}$, and range, and the results as median and range. All calculations were performed with StatView 4.1 (Abacus Concepts Inc, Berkeley, California, USA).

\section{Results}

Infants of mothers with GDM had higher concentrations of total leptin in cord plasma than did infants of healthy mothers $(p<0.05)$. Likewise, the cord plasma concentrations of free and bound leptin, as well as the percentage of free leptin, were significantly higher in infants of mothers with GDM (all p < 0.05).

A significant decrease from birth to 3 days of age was observed in the concentrations of total, free, and bound leptin in infants of mothers with GDM and infants of healthy mothers (table 2). The percentage of free leptin 
Table 2 Plasma concentrations of total, free, and bound leptin, and percentage of free leptin at birth and at 3 days of age, in infants born to either mothers with gestational diabetes mellitus (GDM) or healthy mothers

\begin{tabular}{lrc}
\hline & Infants of GDM mothers & Infants of healthy mothers \\
\hline Leptin concentration in cord plasma $(\mu \mathrm{g} / \mathrm{l})$ & $15.0(3.2-43.8)^{\star}$ & $7.2(2.4-26.8)$ \\
Total & $8.5(1.8-27.2)^{\star}$ & $3.4(1.1-13.9)$ \\
Free & $5.5(1.4-16.6)^{\star}$ & $3.5(1.4-12.9)$ \\
Bound & $58.7(49.1-70.0)^{\star}$ & $52.6(40.6-57.5)$ \\
Percentage of free leptin & & \\
& & $1.7(0.6-2.6) \dagger$ \\
Leptin concentration at 3 days of age $(\mu \mathrm{g} / \mathrm{l})$ & $0.9(0.5-1.2) \dagger$ \\
Total & $1.8(1.0-3.7) \dagger$ & $0.8(0.6-1.4) \dagger$ \\
Free & $1.0(0.5-1.9) \dagger$ & $50.4(44.5-56.2) \dagger \dagger$ \\
Bound & $0.8(0.5-1.8) \dagger$ & \\
Percentage of free leptin & $55.3(49.6-67.7)^{\star}$ & \\
\hline
\end{tabular}

Values are median (range).

${ }^{\star} \mathrm{p}<0.05$ compared with infants of healthy mothers.

tp $<0.005$ compared with at birth.

t†p $<0.05$ compared with at birth.

remained stable from birth to 3 days of age in infants of mothers with GDM. In infants of healthy mothers, a significant decline from birth to 3 days of age was observed ( $p<0.05)$.

At 3 days of age, no significant difference existed in leptin levels between infants of mothers with GDM and healthy mothers (table 2). Infants of mothers with GDM tended to have somewhat higher concentrations of free leptin, but this difference did not reach statistical significance $(p=0.08)$. The percentage of free leptin was also higher in infants of mothers with GDM at 3 days of age ( $<<0.05$; table 2$)$.

In all infants, cord plasma concentrations of total, free, or bound leptin correlated with none of the clinical variables presented in table 1 (data not shown). At 3 days of age, a correlation existed between the percentage of free leptin and BMI $(r=0.487, \mathrm{p}=0.0016)$. In multiple regression analysis, with the percentage of free leptin at 3 days of age as dependent, and GDM of the mother and BMI at 3 days of age as independent variables, the percentage of free leptin remained significantly dependent on GDM of the mother (partial $r=0.432, \mathrm{p}=0.028)$, but not on BMI.

\section{Discussion}

Although infants of mothers with GDM and those of healthy mothers were similar in terms of patient characteristics, the former had higher concentrations of total, free, and bound cord plasma leptin. These data therefore suggest that the differences in leptin metabolism between infants of mothers with GDM and those of healthy mothers are due to the effect of maternal glucose metabolism. As infants of diabetic mothers have higher insulin concentrations in the cord plasma, ${ }^{15}{ }^{17}$ this, or enhanced glucose metabolism, or both ${ }^{12-14}$ may have stimulated leptin secretion in utero to a higher extent. It is also possible that some of the difference in leptin concentration between infants of healthy mothers and those with GDM is due to placental leptin production, ${ }^{38}$ because it has been shown that placental leptin protein content is higher in insulin treated diabetic pregnant women than in healthy pregnant women. ${ }^{15}$ This finding is in accordance with recent data showing that cord plasma leptin concentrations are elevated to the same extent in infants of mothers with either GDM or type
1 diabetes compared with concentrations in infants of healthy mothers. ${ }^{17}$ They also concluded that the difference was explained mostly by enhanced placental leptin production.

In infants of mothers with GDM, we observed an increase in bound leptin levels at birth, suggesting that maternal GDM increases the concentrations of leptin binding proteins in the fetoplacental circulation. The situation appears to be analogous to that in pregnant women with type 1 diabetes, who have higher levels of soluble leptin receptor. ${ }^{11}$ Taken together, these data show that insulin or maternal hyperglycaemia, or both, may participate in the regulation of levels of free leptin and leptin binding protein.

In the infants in our study, the concentration of total leptin decreased significantly from birth to 3 days of age, confirming previous observations. ${ }^{27-32}$ Similarly, the concentrations of bound and free leptin decreased. Interestingly, in our infants, the decrease in free leptin concentration from birth to 3 days was similar to that in lean adults as a result of 24 hours of fasting, ${ }^{8}$ suggesting that, during the early postnatal period when the infant adapts to extrauterine life, the decrease in total and free leptin may be a physiological adaptation to reduce the inhibitory actions of leptin on food intake.

By 3 days of age, the differences in concentrations of total and bound leptin between infants of mothers with GDM and healthy mothers were no longer significant. However, at 3 days of age, the concentration of free leptin tended to be higher in infants of mothers with GDM. This may reflect the significant decline observed in the percentage of free leptin in infants of healthy mothers, whereas in infants of mothers with GDM, the percentage of free leptin at 3 days of age did not differ from that at birth. In infants of mothers with GDM, the percentage of free leptin was significantly higher at both birth and 3 days of age. Although the number of infants studied is comparatively small, these results suggest an effect of maternal glucose metabolism on fetal leptin metabolism. Whether they merely reflect a short term metabolic difference between these infants resulting from abnormal glucose homoeostasis in utero or predict long term metabolic effects in infants of mothers with GDM warrants further study. It has been reported that the offspring of mothers with either GDM or type 1 diabetes are at increased risk of childhood obesity and later development of disorders of glucose metabolism. ${ }^{39-41} \mathrm{~A}$ recent result showed that, at 1 day of age, the differences in leptin concentrations between infants of healthy mothers and those with either GDM or type 1 diabetes were no longer significant. ${ }^{42}$ Therefore this result favours the idea that the differences in leptin concentration observed at birth are a transient phenomenon which normalises as fetal adaptation proceeds.

The leptin binding activity that is compatible with the affinity of the soluble leptin receptor is higher in prepubertal children than in infants and adults, but appears to be similar in infants and adults. ${ }^{43}$ In all the infants in our study, the percentage of free leptin was about $55 \%$, which 
is comparable to that in lean adults. ${ }^{8}$ Free and bound leptin appear to behave as different compartments, and physiological alterations such as fasting affect the percentage of free leptin. ${ }^{8}$ In our study, it is of interest to note that, during the first few postnatal days, the infants of mothers with GDM had a higher, relatively constant, percentage of free leptin, whereas in infants of healthy mothers the percentage of free leptin decreased. Whether this indicates leptin resistance in infants of mothers with GDM, as in obese adults, ${ }^{8}$ remains to be established. In adults, the percentage of free leptin is related to the degree of obesity and $\mathrm{BMI}^{8-10}$; accordingly we observed a correlation between the percentage of free leptin and BMI at 3 days of age. However, as indicated by multiple regression analysis, this correlation appeared to be a function of maternal GDM, and was not explained by BMI per se.

In conclusion, infants of mothers with GDM have higher concentrations of total, free, and bound leptin in cord plasma than do offspring of healthy mothers, suggesting that enhanced glucose metabolism or insulinaemia, or both, regulate fetoplacental leptin secretion. By 3 days of age, plasma concentrations of total, free, and bound leptin decrease in all infants.

We thank the personnel of Helsinki City Maternity Hospital for their cooperation. This study was supported by the Finnish
Society for Pediatric Research and Finska Läkaresällskapet, the Society for Pediatric Research and Finska Läkaresällskapet, the
Helsinki University Central Hospital Research Fund, the Emil Helsinki University Central Hospital Research Fund, the Emil Aaltonen Foundation, Finnish Academy of Science (grant No 46778), Finnish Cultural Foundation, Jalmari and Rauha Ahokas Foundation, the Research Foundation of Orion Corporation, Helsingin Sanomat

1 Zhang Y, Proenca R, Maffei M, et al. Positional cloning of the mouse obese gene and its human homologue. Nature 1994;372:425-32.

2 Pelleymounter MA, Cullen MJ, Baker MB, et al. Effects of the obese gene product on body weight regulation in $\mathrm{ob} / \mathrm{ob}$ mice. Science 1995;269:540-3

3 Rosenbaum M, Nicolson M, Hirsch J, et al. Effects of weight change on plasma leptin concentrations and energy

4 Woods SC, Seeley RJ, Porte D Jr, et al. Signals that regulate food intake and energy homeostasis. Science 1998;280:1378-83.

5 Cioffi JA, Shafer AW, Zupancic TJ, et al. Novel B219/OB receptor isoforms: possible role of leptin in hematopoiesis receptor isoforms: possible role of leptin in

6 Hoggard N, Hunter L, Duncan JS, et al. Leptin and leptin receptor mRNA and protein expression in the murine

7 Mikhail AA, Beck EX, Shafer A, et al. Leptin stimulates fetal and adult erythroid and myeloid development. Blood 1997;89:1507-12.

8 Sinha MK, Opentanova I, Ohanessian JP, et al. Evidence of free and bound leptin in human circulation. Studies in lean and obese subjects and during short-term fasting. $\mathcal{F}$ Clin Invest 1996;98:1277-82.

9 Houseknecht KL, Manzoros CS, Kuliawat R, et al. Evidence for leptin binding to proteins in serum of rodents and humans: modulation with obesity. Diabetes 1996;45:163843.

10 Malmström R, Taskinen MR, Karonen SL, et al. Insulin increases plasma leptin concentrations in normal subjects increases plasma leptin concentrations in normal subjects

11 Utriainen T, Malmström R, Mäkimattila S, et al. Supraphysiological hyperinsulinemia increases plasma leptin
concentrations after $4 \mathrm{~h}$ in normal subjects. Diabetes concentrations afte.

12 Mueller WM, Gregoire FM, Stanhope KI, et al. Evidence that glucose metabolism regulates leptin secretion from cultured rat adipocytes. Endocrinology 1998;139:551-8.

13 Leonhardt W, Horn R, Brabant G, et al. Relation of free and specifically bound leptin to insulin secretion in patients with impaired glucose tolerence (IGT). Exp Clin Endocrinol Diabetes 1999;107:46-52.
14 Lewandowski K, Horn R, O’Callaghan CJ, et al. Free leptin, bound leptin and soluble leptin receptor in normal and diabetic preg

15 Lepercq J, Cauzac M, Lahlou N, et al. Overexpression of placental leptin in diabetic pregnancy: a critical role for insulin. Diabetes 1998;47:847-50.

16 Shekhawat PS, Garland JS, Shivpuri C, et al. Neonatal cord blood leptin: its relationship to birth weight, body mass index, maternal diabetes and steroids. Pediatr Res 1998;43:338-43.

17 Persson B, Westgren M, Celsi G, et al. Leptin concentrations in cord blood in normal newborn infants and offspring of diabetic mothers. Horm Metab Res 1999;31:467-71.

18 Gross GA, Solenberger T, Philpott T, et al. Plasma leptin concentrations in newborns of diabetic and nondiabetic mothers. Am f Perinatol 1998;15:243-7.

19 Maffei M, Volpe L, Di Cianni G, et al. Plasma leptin levels in newborns from normal and diabetic mothers. Horm Metab Res 1998; 30:575-80

20 Sivan E, Lin WM, Homko CJ, et al. Leptin is present in human cord blood. Diabetes 1997;46:917-19.

21 Hassink SG, de Lancey E, Sheslow DV, et al. Placental leptin: an important new growth factor in intrauterine and neonatal development? Pediatrics 1997;100:E11-16.

22 Schubring C, Kiess W, Englaro P, et al. Levels of leptin in maternal serum, amniotic fluid and arterial and venous cord blood: relation to neonatal and placental weight. 7 Clin Endocrinol Metab 1997;82:1480-3.

23 Ong KK, Ahmed ML, Sheriff A, et al. The ALSPAC study team. Avon longitudinal study of pregnancy and childhood. F Clin Endocrinol Metab 1999;84:1145-8.

24 Koistinen HA, Koivisto VA, Andersson S, et al. Leptin concentration in cord blood correlates with intrauterine growth. F Clin Endocrinol Metab 1997;82:3328-30.

25 Harigaya A, Nagashima K, Nako Y, et al. Relationship between concentration of serum leptin and fetal growth. $\mathcal{F}$ Clin Endocrinol Metab 1997;82:3281-4.

26 Jaquet D, Leger J, Levy-Marchal C, et al. Ontogeny of leptin in human fetuses and newborns: effect of intrauterine growth retardation on serum leptin concentrations. F Clin Endocrinol Metab 1998;83:1243-6.

27 Marchini G, Fried G, Östlund E, et al. Plasma leptin in infants: relations to birth weight and weight loss. Pediatrics 1998;101:429-32.

28 Helland IB, Reseland JE, Saugstad OD, et al. Leptin levels in pregnant women and newborn infants: gender differences and reduction during the neonatal period. Pediatrics 1998;101:E12.

29 Yura S, Sagawa N, Mise H, et al. A positive umbilical venous-arterial difference of leptin level and its rapid decline after birth. Am f Obstet Gynecol 1998;178:926-30.

30 Matsuda J, Yokota, Iida M, et al. Dynamic changes in serum leptin concentrations during the fetal and neonatal periods. Pediatr Res 1999;45:71-5.

31 Hytinantti T, Koistinen HA, Koivisto VA, et al. Changes in leptin concentration during the early postnatal period: adjustment to extrauterine life? Pediatr Res 1999;45:197201 .

32 Harigaya A, Onigata K, Nako Y, et al. Role of serum leptin in the regulation of weight gain in early infancy. Biol Neonate 1999;75:234-8.

33 Pihkala J, Hakala T, Voutilainen P, et al. Uudet suomalaiset sikiön kasvukäyrät. Duodecim 1989;105:1540-6.

34 Hyvönen K. Gestaatiodiabeteksen esiintyvyys ja seulonta. Publications of the University of Kuopio. Original reports 6/1991

35 Teramo K, Haukkamaa M, Leinonen P, et al. Diabetes ja raskaus. Suomen lääkärilehti 1993;26:2451-6.

36 Ma Z, Gingerich RL, Santiago JV, et al. Radioimmunoassay of leptin in human plasma. Clin Chem 1996;42:942-6. 37 Karonen S-L, Koistinen H, Nikkinen P, et al. Is brain uptake
of leptin in vivo saturable and reduced by fasting? Eur $\mathcal{F}$ Nucl Med 1998;25:607-12

38 Masuzaki, H, Ogawa Y, Sagawa N, et al. Nonadipose tissue production of leptin: leptin as a novel placenta-derived production of leptin: leptin as a novel placentar

39 Silverman BL, Rizzo T, Green OC, et al. Long-term prospective evaluation of offspring of diabetic mothers. Diabetes 1991;40:121-5.

40 Pettitt DJ, Bennett PH, Saad MF, et al. Abnormal glucose tolerance during pregnancy in Pima indian women. Longterm effects on offspring. Diabetes 1991;40(suppl 2):12630.

41 Pettitt DJ, Nelson RG, Saad MF, et al. Diabetes and obesity in the offspring of Pima indian women with diabetes during pregnancy. Diabetes Care 1993;16(suppl 1):310-13.

$42 \mathrm{Ng}$ PC, Lam CWK, Lee CH, et al. Leptin and metabolic hormones in infants of diabetic mothers. Arch Dis Child Fetal Neonatal Ed 2000;83:193-7.

43 Quinton ND, Smith RF, Clayton PE, et al. Leptin binding activity changes with age: the link between leptin and puberty. F Clin Endocrinol Metab 1999;84:2336-41. 